\title{
LAS REPRESENTACIONES SOCIALES DE LA HISTORIA AL SERVICIO DE LA DIDÁCTICA EN EDUCACIÓN SUPERIOR
}

\author{
Íñigo Mugueta Moreno ${ }^{1}$ \\ Universidad Pública de Navarra
}

\begin{abstract}
RESUMEN: En este trabajo se han pretendido analizar algunas de las representaciones de la Historia más extendidas entre los alumnos del Grado de Maestro en Educación Primaria, y posteriormente desarrollar un procedimiento didáctico eficaz para desarrollar en dichos alumnos una capacidad crítica que les permita enfrentarse a un conocimiento histórico que hoy resulta tan dependiente de tópicos extendidos por redes sociales, internet y todo un variado "universo transmedia". Las representaciones sociales de la Historia entre los alumnos se analizarán por medio de encuestas, tratadas con criterios cualitativos y cuantitativos, mientras los procedimientos didácticos, desarrollados con alumnos del mismo Grado, del Master de Formación del Profesorado de Secundaria, y del Curso de Adaptación a los Grados de Maestro (siempre alumnos universitarios), se valorarán en su conjunto de forma cualitativa. Los resultados nos permitirán analizar algunas de las ventajas y dificultades de una metodología de enseñanza activa que parta de los intereses y conocimientos previos de los alumnos, aun cuando estos constituyan realidades alternativas al conocimiento científico.
\end{abstract}

PALABRAS CLAVE: Representación social, educación superior, historia medieval, conocimientos previos, didáctica.

\section{SOCIAL REPRESENTATIONS OF HISTORY AT THE SERVICE OF TEACHING PRACTICE IN HIGHER EDUCATION}

\begin{abstract}
This study sets out to analyse some of the most widespread representations of History maintained by Primary Education Degree students, and to set up an efficient teaching procedure to develop critical capacity among these students so that they can approach historical knowledge, nowadays so
\end{abstract}

1 Este trabajo se ha realizado en el marco del proyecto de investigación Historia y Videojuegos. El impacto de los nuevos medios de ocio sobre el conocimiento del pasado medieval (HAR2011-25548), financiado por el Ministerio de Economía y Competitividad. 
subject to clichés spread by the social networks, the Internet and a whole and varied "transmedia universe". Social representations of History among the students will be analysed through questionnaires, based on qualitative and quantitative criteria, while the teaching methods, developed together with students from the Teacher Training Degree course, the Master's Degree Course for Secondary Teacher Training, and the Pedagogical Training Course for Primary Education Degree students (always university students) will be assessed qualitatively as a unit. The results will enable us to analyse some of the advantages and difficulties involved in an active teaching methodology based on the interests and previous knowledge of the students, even when these constitute alternative realities to scientific knowledge.

KEYWORDS: Social representation, higher education, mediaeval history, prior knowledge, teaching.

Recibido: $17 / 04 / 2015$

Aceptado: 11/06/2015

Correspondencia: Iñigo Mugueta Moreno, Departamento de Geografía e Historia, Edificio de Los Acebos, Campus Arrosadía, 31006 Pamplona. Email: inigo.mugueta@ unavarra.es.

\section{INTRODUCCIÓN Y ANTECEDENTES}

En este trabajo nos hemos propuesto estudiar, en primer lugar, el modo en el que los alumnos del grado de Maestro en Educación Primaria de la Universidad Pública de Navarra comprenden la Edad Media. Una vez que se pudo comprobar por medio de cuestionarios de conocimientos previos la presencia de un buen número de concepciones históricas estereotipadas, se diseñó un procedimiento didáctico destinado a mostrar a estos alumnos la vulnerabilidad de nuestro conocimiento histórico frente a las informaciones históricas emitidas desde diferentes canales de información: publicidad, internet, medios de comunicación... Y así, en segundo lugar analizamos los resultados de la acción didáctica emprendida con el fin de hacer conscientes a los alumnos de esa vulnerabilidad.

Por tanto, partimos en este trabajo de la hipótesis de que el análisis de una representación social de la Historia (una forma de conocimiento de la Historia generada a través de la interacción social y que consigue simplificar y hacer inteligible la realidad social para su uso cotidiano), puede convertirse en un estímulo atractivo para el estudio y la investigación de la Historia.

Los investigadores se enfrentan a esta realidad de maneras y con denominaciones diferentes: desde la perspectiva de la sociología se habla de representaciones sociales o colectivas (Sosa y otros, 2013; y Rodríguez Salazar y García Curiel, 2007), basados en la conocida teoría del psicólogo social francés, Serge Moscovici (1989) y no ceñidas únicamente a la componente histórica; en el terreno común de historiadores y sociólogos se maneja asiduamente el concepto "memoria colectiva" acuñado por 
Halbwachs (2004), que alude a procesos -normalmente dirigidos a través del poder del Estado- de construcción colectiva de una identidad común. En el campo de la didáctica es habitual englobar este tipo de cuestiones dentro de un amplio "pensamiento histórico" de los alumnos" (Grupo Valladolid, 1994), que incluiría el manejo de tópicos y estereotipos, entre otros; al respecto M. Carretero (2007: 36-40) distingue tres "sentidos de la Historia", o tres niveles complementarios y relacionados de estructuración de las narraciones, que serían la Historia académica, la escolar y la cotidiana. El esquema del profesor Carretero plasma con precisión la dificultad de la construcción de una Historia escolar situada entre las fuerzas divergentes de la Historia académica y la "cotidiana". En todo caso, la construcción de la Historia en torno a mitos y estereotipos es una realidad constatada incluso en el entorno escolar, que en algunos momentos se ha servido de ellos con finalidades identitarias e ideologizantes, en concordancia con algunas de las influencias ejercidas por las representaciones sociales, según señala Jodelet (1989: 37-38); Emilio Castillejo (2008) engloba estos mitos y tópicos escolares dentro del concepto "creencias históricas dominantes", en su estudio sobre los manuales escolares del franquismo. Por último, en los últimos años -en especial en España- ha cobrado importancia el concepto "memoria histórica" (Ruiz Torres, 2007; Espinosa Maestre, 2006), ligado más a la recuperación de olvidos voluntarios, ideológicos y colectivos, como en el caso de los vencidos de la Guerra Civil española, y que aquí nos interesa más tangencialmente.

Por nuestra parte, hemos preferido el concepto "representación social" de Moscovici, que consideramos más adecuado para la problemática que planteamos, y muy operativo para el "mundo 2.0", de intercambio de informaciones en todas direcciones, y en el que las representaciones colectivas más poderosas ya no son propiamente políticas, sino también y especialmente, económicas, y ligadas al consumo y a las modas. Dentro de este conjunto de concepciones sociales se encuentran los tópicos o estereotipos, las teorías científicas anticuadas y superadas -que en ocasiones tardan en desaparecer- y las creaciones literarias, fantásticas o para-históricas, muchas veces tejidas junto a pinceladas de certezas históricas, y caracterizadas en general por una fuerte componente visual. Lo característico de todas ellas -en tanto que representaciones sociales y colectivas- es que sustituyen al conocimiento científico, lo simplifican y lo hacen inteligible -de manera ingenua o no-, para poder usarlo en el lenguaje cotidiano, y también con otros objetivos diversos (publicidad, comunicación...) (Jodelet, 1989; Moscovici, 1989; Moliner, 2001; Rodríguez Salazar y García Curiel, 2007).

Las pedagogías constructivistas nos han enseñado a valorar los conocimientos previos de los alumnos, dado que estos actúan como conceptos inclusores que facilitan el aprendizaje (González y Novak, 1993). En una sociedad y un tiempo cambiantes, donde el ritmo de los cambios se acelera día a día y las informaciones circulan a velocidades vertiginosas de un extremo a otro del globo terráqueo, para el profesor de Historia resulta cada vez más complejo -pero también más pertinente- averiguar qué saben -o qué creen saber- los alumnos sobre la Historia y sobre cada periodo histórico concreto.

El interés por conocer cómo entiende nuestra sociedad la Historia se está desarrollando de manera amplia en diversos ámbitos académicos (historiadores, especialistas en comunicación, didactas...), y referido a diferentes épocas históricas. Algunos 
historiadores han detectado la importancia de analizar qué aspectos de la Historia interesan en nuestro presente, y cómo se perciben. La conclusión generalizada es que el mundo actual comprende la Historia de manera superficial, utilizando tópicos o estereotipos (Grupo Valladolid, 1994; Liceras, 2003), generalizaciones, simplificaciones, y errores conceptuales diversos que se mezclan de manera diferente, como en una coctelera $(S a n z, 2009)^{2}$. Otra característica de nuestra sociedad es que transmite a una velocidad vertiginosa esas concepciones alternativas de la Historia, utilizando infinidad de canales: redes sociales, internet en general, medios de comunicación, cine, televisión, novela, videojuegos... en fin, a través del denominado universo transmedia (Ferrés, 2000; Falcón y Díaz Aguado, 2014). Á. Liceras (2003) define a la perfección los conceptos tópico, estereotipo y prejuicio, y los sitúa dentro de la problemática que aquí pretendemos describir.

Hablamos -por tanto- de la existencia de una cultura histórica que podemos denominar de baja intensidad, que al mismo tiempo posee un gran prestigio social, un fuerte arraigo en las convicciones de la población con un nivel cultural medio o bajo, y un carácter netamente acrítico. Diversos autores -que no podremos citar aquí con exhaustividad- lo detectan en sus respectivos terrenos de estudio: la prehistoria (Sanz, 2009), diversos momentos y lugares ligados a la Antigüedad en general (Prieto, 2011), o a realidades más concretas como Esparta (Fornis, 2011; Ortega, 2007), Troya (Prieto, 2005), y Roma (Cano, 2014; Serrano, 2012), y finalmente, también a la Edad Media(Barrio, 2008; Galván, 2008; Jiménez Alcázar, 2011). Son sólo algunos de los nombres y épocas históricos cuyos tópicos extendidos han sido ya analizados a partir de las diferentes interpretaciones aparecidas en el mencionado universo transmedia. Quienes lo analizan hablan de "un sendero de tópicos y falacias", de una sociedad "siempre complaciente con todo lo que suponga entretenimiento", de la creación de productos históricos "light", o de nombres históricos convertidos en "marcas registradas" (Fornis, 2011; Prieto, 2005; Ortega, 2007). Por tanto, se trata de una cultura histórica difícil de combatir: está arraigada en las mentalidades colectivas, está tan presente en todos los órdenes de la vida cotidiana que es difícil escapar a ella, y se manifiesta de forma sibilina con un ecléctico pandemónium de ideas verídicas, verdades a medias, simplificaciones, hipérboles, metáforas y tópicos varios.

Por nuestra parte, en los últimos años hemos pretendido analizar la presencia de estas representaciones sociales de la Historia a través de dos canales muy diferentes centrados en la época medieval: los libros ilustrados de divulgación histórica dirigidos a un público infantil y juvenil y los videojuegos de temática histórica (Mugueta y Tobalina, 2015). Además de las consabidas apariciones de tópicos relacionados con la Ilamada "Edad Media oscura" y/o "fantástica", se han podido detectar otros igual de interesantes, como el predominio de las formas externas de la Baja Edad Media (castillos, ropajes, armas y armaduras), para caracterizar a todo el periodo medieval, y de la Plena Edad Media en cuanto a los principios socio-económicos (relaciones

2. J.L. Sanz (2009) sitúa la mitogénesis de los dinosaurios en la interacción entre los resultados de la investigación paleontológica y su proyección en los medios de comunicación de masas. Este autor ha conceptualizado incluso lo que denomina "mito dinosauriano", en torno a cinco pilares: sincronización de dinosaurios y humanos; convivencia entre ambos; modos de vida de los dinosaurios; criaturas dinosauroides en el cine japonés; y relaciones entre dragones y dinosaurios. 
feudo-vasalláticas) que representarían el estereotipo más habitual del medievo. En cualquier caso, nos parece interesante renovar el acercamiento a estas cuestiones, tan afectadas por el actual incremento de la información accesible a través de las nuevas redes y tecnologías de la información.

Por otro lado, que la pedagogía se fije en tópicos, estereotipos o concepciones alternativas del saber académico y científico, no supone una novedad. Wandersee, Mintzes y Novak (1994) sistematizaron y pusieron de manifiesto la importancia de trabajar con lo que denominan errores conceptuales o concepciones alternativas a las teorías científicas, si bien lo hicieron en el terreno de las ciencias experimentales (González, Morón y Novak, 2001). Ellos Ilamaron la atención sobre el peligro de ignorar las concepciones divergentes que manejan los alumnos, ya que estos funcionan como conocimientos previos, y las enseñanzas de un docente se insertan o superponen sobre ellos, produciendo finalmente un resultado de aprendizaje indeseable. Otros autores proponen combatir el error desde el error (Astolfi, 1997; Sánchez Rivera, 2013), una cuestión en la que -por desgracia- el mundo académico no puede jactarse de ser pionero. En cambio las industrias editorial ${ }^{3}$, cinematográfica o lúdica han comprendido perfectamente el interés social generado por las representaciones sociales más extendidas sobre la Historia ${ }^{4}$.

Los docentes y especialistas en didáctica, por su parte, también preguntan a los alumnos por las fuentes del conocimiento no formal de la Historia (Grupo Valladolid, 1994; García Pujades, 2013; Rivero Gracia, 2009; Navarro Espinach, 2011), y los resultados confirman que los estudiantes de secundaria son receptores de esa cultura histórica popular donde se mezclan elementos reales con otros míticos, alternativos, imaginarios o simplemente incorrectos. Es sintomática la aparición de El señor de los anillos o Juego de Tronos como libros o películas de carácter histórico tanto entre las menciones de alumnos de Educación Secundaria (García Pujades, 2013), como entre estudiantes de Universidad 5 .

Finalmente, tampoco resulta del todo novedoso plantear estrategias didácticas basadas en el error conceptual (Briceño, 2009), que se convierte así en un potente anclaje conceptual capaz de permitir un mayor interés del alumno, y una mejor comprensión del hecho histórico estudiado ${ }^{6}$. Se trata en definitiva del denominado "modelo del cambio conceptual", que busca activar el conocimiento de los alumnos,

3. Baste mencionar el número 32 (nov. 2010) de la revista divulgativa Muy Historia, dedicada a "Mentiras y mentirosos de la Historia", con el subtítulo: "Las 15 Super Trolas. La Atlántida, Tutankamón, Nazca, los Sabios de Sión, Roswell, el falso alunizaje...", aunque los ejemplos serían innumerables en esta y otras publicaciones divulgativas similares.

4. En la televisión, los canales o programas de contenidos históricos hace tiempo que han descubierto la potencialidad del error conceptual histórico como elemento que atrae la atención del gran público, como es el caso del conocido programa español "Cuarto Milenio", algunos de cuyos contenidos son consultables on-line. Partiendo de claros errores conceptuales, el programa trata de aplicar una explicación científica al misterio.

5. Los datos que nosotros mismos facilitaremos muestran cómo -en menor medida- también entre los alumnos universitarios persiste el error de considerar estos "pasados alternativos" como "históricos".

6. Resultan interesantes en este aspecto las reflexiones de E. Martos Núñez y A. Martos García (2012), sobre el papel didáctico que pueden jugar los mitos o espantos en la educación y el desarrollo de "competencias sociales y culturales, tales como preservar la memoria de la comunicada o integrar todos estos símbolos/mitos en un lenguaje plástico, ritos, costumbres o conmemoraciones". 
generar un conflicto entre las ideas de los sujetos y la información científica, y finalmente superar las ideas iniciales gracias al acceso a una idea más avanzada (Grupo Valladolid, 1994; Carretero, Pozo y Asensio, 1989).

Como consecuencia de todo ello, este trabajo entendemos que las representaciones sociales de la Historia constituyen puntos de partida interesantes para el trabajo en el aula. Poseen un gran potencial motivador debido a su fuerza comunicadora, a su gran atractivo visual -que se acrecienta día a día- y a la sencillez de sus significados. Y sobre todo, permiten planificar procedimientos didácticos basados en los gustos, intereses y conocimientos previos de los alumnos, que estimulen un aprendizaje activo por su parte, destinado finalmente al logro de reflexiones autónomas sobre el propio conocimiento histórico, y sobre la manera de adquirirlo. Un aprendizaje que en definitiva resulte útil en nuestro presente y en el futuro de los alumnos.

Aquí plantearemos tanto los resultados de las encuestas realizadas a unos 100 alumnos de $2^{\circ}$ curso del Grado de Maestro en Educación Primaria, como algunas conclusiones del procedimiento didáctico llevado a cabo por alumnos del mismo Grado de Maestro en Educación Primaria, del Curso de Adaptación a los Grados de Maestro, y del Máster de Formación del Profesorado de Educación Secundaria, a lo largo de dos cursos académicos. Por tanto, en la primera parte trataremos de presentar los datos obtenidos en las encuestas por medio de una exposición basada en un análisis cualitativo/cuantitativo, y en la segunda utilizaremos una metodología exclusivamente cualitativa, analizando de manera global algunas diferencias en la manera de abordar las tareas propuestas por parte de los diferentes alumnos, que nos han hecho plantear algunas hipótesis de trabajo para el futuro.

\section{Objetivos}

Este trabajo nació a partir de las respuestas que los alumnos de segundo de magisterio dieron a varios cuestionarios sobre "fuentes del conocimiento no formal de la historia", realizados en el curso 2012/2013. Los resultados Ilevaron a repetir el experimento de una manera más ordenada y sistemática en el curso 2013/2014 con 105 estudiantes de $2^{\circ}$ de magisterio, y a proponer una metodología de trabajo que permitiera desarrollar en los alumnos una actitud crítica, y una capacidad de comprender el papel del maestro como mediador entre el saber experto y el saber popular. Destinamos en la asignatura toda una unidad temática a estudiar el método histórico y las fuentes históricas, y a comprender cómo trabaja un historiador. Después pasamos a analizar el saber popular, las representaciones alternativas de la Historia, y su difusión por diferentes canales de información durante los cursos 2013/2014 y 2014/2015.

Los cuestionarios distribuidos entre los alumnos no pretendían convertirse en un reflejo de las representaciones sociales más extendidas sobre la Historia en general o el medievo en particular. A ese cometido hemos dedicado otros estudios parciales que pretenden ir constituyendo un corpus complejo de fuentes con las que reconstruir una visión amplia sobre la manera en que nuestra sociedad comprende y utiliza el pasado. El objetivo de estos cuestionarios era determinar el grado de 
presencia de concepciones erróneas o aberrantes de la Historia en la Universidad, y más en concreto entre los futuros docentes de la Etapa de Educación Primaria.

La segunda parte de esta investigación se basa en la convicción de la necesaria puesta en marcha de metodologías activas en la enseñanza de la Historia, fundadas sobre la construcción del conocimiento por parte del alumno, y que logren su implicación por medio del descubrimiento y la indagación (Tribó, 2005: 41-66). Como ha sido indicado ya por otros autores, se trata de enseñar a investigar el pasado, pero también de utilizarlo como instrumento de conocimiento útil del presente -como ya señalara entre otros G. Zaragoza (1989)-, y de las diferencias que hoy encontramos entre el saber experto y el saber popular, con la Historia académica ejerciendo una función de bisagra (Carretero, 2007). En este sentido, proponemos que las representaciones sociales de la Historia -incluidos en ellas los tópicos más extendidos-, sean usadas como detonante del interés del alumno por indagar en la Historia, y en consecuencia como incentivo para lograr un mejor conocimiento histórico. Ello nos permitirá incidir al menos en cuatro aspectos que consideramos esenciales dentro de la formación del pensamiento histórico:

- Atraer el interés de los alumnos sobre las representaciones más atractivas de la Historia, aun cuando puedan resultar erróneas.

- Desarrollar metodologías de aprendizaje activo por parte de los alumnos, relacionadas con la resolución del conflicto entre saber experto y saber popular, con la indagación y el análisis de fuentes primarias y secundarias.

- Fomentar el pensamiento crítico de los alumnos con respecto a las informaciones históricas recibidas a través de las fuentes secundarias.

- De acuerdo con las necesidades de nuestra sociedad de la información, desarrollar una capacidad crítica de las informaciones adquiridas en el presente por medio de diferentes canales de información (fuentes periodísticas, universo transmedia, redes sociales, internet en general...), y conseguir que la Historia resulte una disciplina útil en el presente.

Por tanto, pretendemos presentar algunos resultados, tanto de los cuestionarios iniciales que indagaron sobre los conocimientos previos de los alumnos, como del procedimiento didáctico que se diseñó para enfrentar a los alumnos a algunos de los conceptos o épocas históricas más adulteradas por la cultura popular actual.

\section{Metodología}

\section{Análisis de las representaciones sociales de los alumnos del Grado de Maestro}

La experiencia se realizó con una muestra de 105 alumnos de $2^{\circ}$ curso del Grado de Maestro en Educación Primaria (UPNA), divididos en dos clases. En primer lugar se realizaron dos sencillos cuestionarios para conocer las representaciones históricas más habitualmente manejadas por estos alumnos sobre la Edad Media: en el primero se preguntó por las fuentes del conocimiento no formal del alumnado sobre la Historia; en el segundo se utilizó como excusa la época medieval (rica en concepciones alternativas). 
El primer cuestionario -respondido por 76 alumnos- pretendía conocer las fuentes del conocimiento no formal de los alumnos sobre la Historia, y contenía tres sencillas preguntas:

- ¿Has leído alguna novela histórica? ¿Cuál(es)?

- ¿Ves series o películas históricas? ¿Cuáles?

- ¿Juegas a videojuegos históricos? ¿Cuáles?

En el segundo cuestionario -respondido ya sólo por 95 alumnos- se dio libertad a los alumnos para responder a dos preguntas básicas sobre la Edad Media:

- ¿Qué caracteriza, en tu opinión, a la Edad Media?

- ¿Qué nombres propios más importantes asocias a la Edad Media?

Este segundo cuestionario incluía una segunda parte en la que se proponía a los alumnos adivinar qué personajes eran medievales y qué otros personajes no lo eran, entre una lista de 26 personajes históricos (políticos, reyes, artistas, literatos, filósofos), de diferentes épocas.

El objetivo esencial de estos cuestionarios era conocer someramente los conocimientos previos de los alumnos sobre Historia Medieval. La publicación del trabajo de García Pujades (2013) sobre los conocimientos previos de los alumnos de Educación Secundaria sobre la Edad Media, nos permitirá realizar una comparación entre las respuestas de los alumnos de Educación Secundaria y los de Universidad.

\section{Elaboración y análisis del procedimiento didáctico realizado}

Tras un análisis cualitativo y cuantitativo de los datos facilitados por los alumnos, se procedió a la propuesta de un procedimiento didáctico que adquirió la forma de una "práctica por grupos", a la que se dedicaron tres sesiones prácticas de hora y media. Los alumnos realizaban este trabajo, por tanto, a lo largo de casi un mes. El trabajo venía contextualizado por cuatro clases teóricas previas, de dos horas cada una; una sobre el método histórico, dos sobre las fuentes históricas y una cuarta sobre las propias representaciones sociales de la Historia.

La experiencia se repitió de manera similar al año siguiente, con otros 92 alumnos del Grado de Educación Primaria, en el Máster de Formación del Profesorado de Secundaria ( 15 alumnos en el primer año y 15 en el segundo), y en el Curso de Adaptación a los Grados de Maestro (30 alumnos el primer año y 3 en el segundo). Así pues, la experiencia ha sido planteada durante los dos años a unos 250 alumnos de edades y formación muy diferentes. El perfil de los alumnos del Grado es de jóvenes de 20 a 30 años -aunque más cercanos a los veinte años- cuya ocupación principal es el estudio del propio grado. En los alumnos del Máster de Secundaria se pueden encontrar perfiles más variados, aunque lo habitual es contar con alumnos recién egresados de grados o licenciaturas de Humanidades (Historia, Geografía, Historia del Arte o Humanidades), o Ciencias Sociales (Ciencias políticas, e incluso Periodismo, aunque de manera excepcional). Por último, los alumnos del Curso de Adaptación a los Grados de Maestro tendían a ser maestros en ejercicio, educadores de centros privados o interinos en el sistema público de enseñanza, si bien había una 
minoría de alumnos egresados en paro de las últimas promociones de diplomados en Magisterio. La metodología fue un tanto diferente en el caso de los alumnos del Master de Secundaria, que necesitaron menos sesiones de trabajo de aula (2 sesiones de práctica, y una tercera de presentación oral de los trabajos).

El trabajo tomaba la forma de una práctica de investigación en la que los alumnos analizaban un tema histórico, a elegir entre una lista -abierta a otras posibilidadesde los más manipulados en el presente (los dinosaurios, las pirámides, Esparta, Troya, los gladiadores, el feudalismo, los templarios, la masonería, el "Salvaje" Oeste...). El trabajo de los alumnos consistía en la elaboración de una presentación en Power Point que recogiese imágenes de usos alternativos de la Historia localizados en internet, con la premisa de que la indagación debía producir resultados en diferentes canales: informaciones periodísticas, fuentes de información icónicas, y también audiovisuales. La presentación de PowerPoint daría testimonio de las diferentes concepciones alternativas localizadas, junto a una pequeña explicación de las mismas. Además, los alumnos debían entregar un informe por escrito sobre el tema elegido, que contuviese los siguientes apartados:

- Saber popular. Concepciones sociales que circulan sobre el tema elegido. Su origen y difusión.

- Cuestionario de conocimientos previos (para alumnos de primaria). Cómo analizar el conocimiento alternativo de nuestros alumnos sobre el tema elegido.

- Saber experto. Realidad histórica en torno al tema elegido.

- Bibliografía. Breve bibliografía (la utilizada en el punto anterior).

Esta propuesta partía de la convicción de que era necesario poner las representaciones sociales del pasado al servicio del proceso de enseñanza-aprendizaje, en una secuencia teórica al servicio del cambio conceptual, que se planteaba en seis pasos:

a) Alianza con el enemigo (usar la concepción alternativa aun cuando resulte evidentemente errónea).

b) Análisis de los conocimientos previos del alumnado.

c) Uso de metodologías activas de indagación/análisis de fuentes expertas que permitan generar un conflicto con el saber popular que los alumnos puedan detectar.

d) Búsqueda del origen de la representación social alternativa elegida.

e) Búsqueda de su difusión en el "universo transmedia" (cine, novela, cómic, videojuego...) e internet, por medio de imágenes.

f) Propuesta de una explicación propia, y reflexión sobre las fuentes consultadas.

El análisis de las informaciones se planteó por medio de una rejilla que permitiera evaluar el grado de comprensión de la actividad por parte de los alumnos. La misma rejilla fue utilizada para evaluar los trabajos de los alumnos de las tres diferentes titulaciones, con la finalidad de poder realizar comparaciones entre unos y otros datos. En ella se analizaban los siguientes logros de los alumnos:

- Elige representaciones de la Historia correctamente.

- Explica las representaciones de la Historia correctamente.

- Comprende el concepto de representación social de la Historia. 
- Es capaz de localizar fuentes secundarias fiables.

- Extrae alguna teoría sobre el origen de la representación social.

- Lee y comprende la bibliografía científica y la explica correctamente en relación con la problemática planteada.

- Plantea representaciones sociales innovadoras, diferentes de las comentadas en clase.

- Plantea representaciones sociales simplistas.

- Es capaz de realizar un planteamiento general de la problemática y no sólo una relación de errores o representaciones concretas.

- Aporta una solución al conflicto planteado por las representaciones sociales.

No se aportarán datos cuantitativos, ya que estimamos que la disparidad de tamaño y composición de los grupos no permitiría una comparación numérica demasiado significativa. Por tanto, la metodología utilizada consistirá en una valoración a grandes rasgos de los resultados más repetidos en cada grupo.

\section{Resultados Y Discusión}

Los dos cuestionarios de conocimientos previos realizados entre el alumnado han sido analizados por medio de metodologías cualitativas y cuantitativas, que pretendían detectar las representaciones sociales de la Historia manejadas por los estudiantes del grado de Maestro. Analizamos por separado las respuestas sobre las fuentes del conocimiento no formal de los alumnos (primer cuestionario), y las respuestas a las tres partes del segundo cuestionario. Finalmente, evaluamos de modo cualitativo los resultados del ejercicio práctico realizado por los alumnos para detectar errores conceptuales.

\section{Cuestionarios de conocimientos previos y de fuentes de información}

Fuentes del conocimiento no formal del alumnado sobre la Edad Media

El primero de los cuestionarios, que pretendía indagar sobre las fuentes del conocimiento no formal de la Historia, arrojó respuestas interesantes a propósito de las series o películas consideradas históricas por los alumnos. 76 alumnos respondieron a la encuesta de los cuales 4 mencionaron Juego de Tronos como una serie histórica, frente a dos alumnos que destacaron El señor de los anillos como película histórica. Por otro lado, la serie histórica más mencionada por los alumnos fue Águila Roja (14 respuestas), si bien se trata de una de las menos rigurosas desde el punto de vista histórico. Finalmente, tres alumnos destacaron la teleserie sobre el héroe mitológico Hércules como una serie de tipo histórico.

Las respuestas "aberrantes" eran Ilamativamente similares a las que obtiene García Pujades en sus encuestas a alumnos de Primaria y Bachillerato, preguntando aquel -eso sí- siempre sobre Edad Media ${ }^{7}$. Por otro lado, sorprende la ausencia de filmes o

7. García Pujades (2013). En las respuestas a sus cuestionarios, las ideas previas de los alumnos demuestran una progresiva reducción de las concepciones de una Edad Media fantástica y oscura, entre El primer curso de la Educación Secundaria Obligatoria (13 años) y el primer curso de Bachillerato (17 años). 


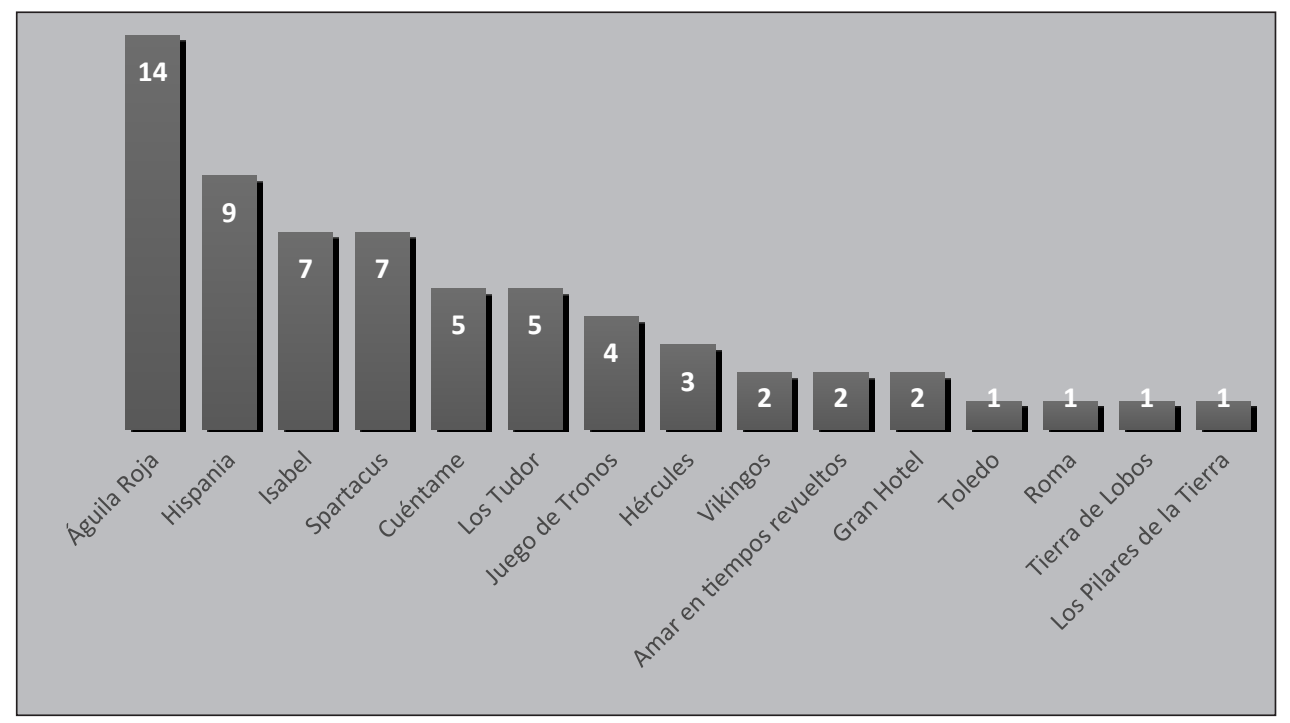

Gráfico 1. Series televisivas de temática histórica mencionadas por los alumnos

series de época contemporánea entre las respuestas de los alumnos, aun existiendo algunos tan conocidos y tanta repercusión como Cuéntame, o El niño del pijama de rayas, o géneros tan conocidos como el western. En general, en las respuestas de los alumnos se percibe un predominio de las teleseries de tipo histórico de época antigua y medieval, como si la simple mención de "lo histórico" provocase en los alumnos la evocación de las épocas más remotas, frente a las más cercanas.

\section{Características atribuidas a la época medieval por el alumnado}

A la vista de la presencia de tópicos y errores diversos concentrados en la época medieval, se decidió pasar a los alumnos un nuevo cuestionario, en este caso centrado en la Edad Media. Esta vez los alumnos que respondieron fueron 95. De nuevo los resultados son similares a los obtenidos por García Pujades, aunque con algunas diferencias interesantes. La primera de las preguntas pretendía averiguar qué aspectos -a juicio de los alumnos- caracterizaban a la época medieval. Se trataba de señalar, a grandes rasgos, las características más importantes del periodo.

Se pudo apreciar la presencia de los lugares comunes extendidos sobre la Edad Media entre las características destacadas por los alumnos, si bien de una manera residual. La Edad Media "oscura" fue citada por 2 alumnos, la falta de higiene, el atraso, y la inquisición, por 3 alumnos en cada caso. De entre las características de la Edad Media más mencionadas por los alumnos se puede destacar la desigualdad social, planteada desde el punto de vista del conflicto entre "clases sociales" (sic) y en la falta de movilidad entre sus miembros. La desigualdad se plantea, sobre todo, desde un punto de vista económico, aludiendo algunos alumnos incluso al "poder adquisitivo" de los pobres o de los ricos. Cabe destacar la confusión de términos en este terreno, pues 19 alumnos citan la "sociedad estamental" como una característica 


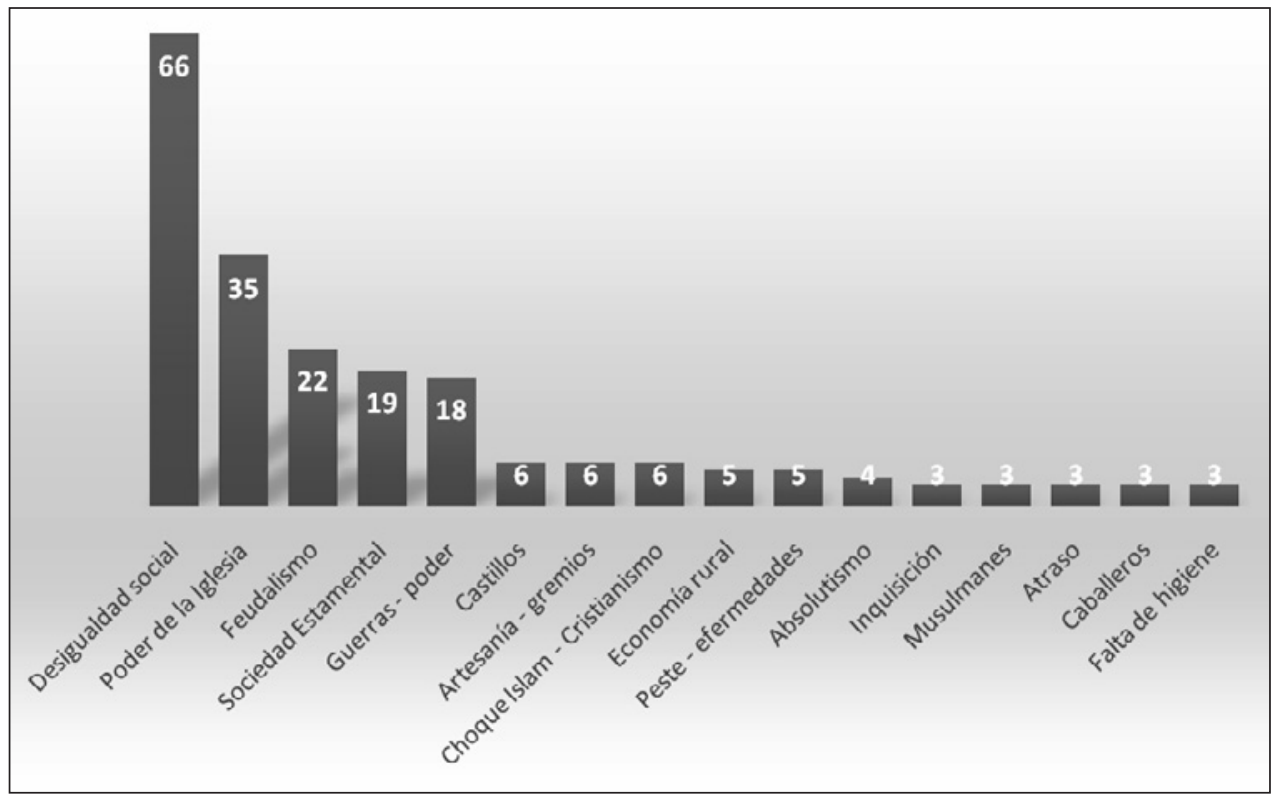

Gráfico 2. Aspectos que caracterizan la Edad Media según los alumnos

de la Edad Media, frente a 22 que mencionan el feudalismo. En algún caso el mismo alumno habla de feudalismo y sociedad estamental, como si fueran sinónimos.

Otro bloque de respuestas se refiere al ejercicio del poder, que atribuyen con diferente número de respuestas a la Iglesia (35), el rey en solitario (4) o la nobleza (3). Una de las facetas del poder medieval para los alumnos, es el desencadenamiento de conflictos bélicos de un modo arbitrario, con la sola pretensión de la expansión territorial. En menor medida el artesanado (6), los castillos (6), o el conflicto cristiano-musulmán (6), son destacados como paradigmáticos de la Edad Media por otros alumnos. Obsérvese que la identificación del hecho religioso con la Edad Media atañe casi en exclusiva a la Iglesia católica, pues sólo tres alumnos mencionan expresamente a los musulmanes, y otros seis de manera indirecta al conflicto cristiano-musulmán, materializado en las Cruzadas o la Reconquista. El asunto parece de alguna relevancia, y volverá a aparecer en las respuestas de los alumnos a otras preguntas.

En conjunto, aunque la presencia de errores conceptuales "de bulto" no es generalizada, se puede observar que la percepción de los alumnos sobre la Edad Media es una suerte de transposición antagónica de la sociedad actual, un contenedor de conceptos opuestos a nuestro sistema de valores: desigualdad, falta de movilidad social, fuerte presencia de una fe cristiana estricta, arbitrariedad del poder, falta de representación política, y resolución de conflictos por la vía militar.

\section{Personajes destacados por el alumnado en la Edad Media}

Otra de las preguntas planteadas a los alumnos pedía la mención de cuantos nombres propios de época medieval conociesen, sin límite en la lista. Se pedía ex- 
presamente nombres de persona, lugar, o institución, señalando previamente que entendíamos la Edad Media como el periodo situado entre los años 476 y 1492 . Globalmente, la primera sorpresa fue que un $25 \%$ de los encuestados dejó la pregunta en blanco por no saber quiénes eran personajes medievales. Después de la realización del test algunos de estos alumnos afirmaron no haber respondido porque no tenían la seguridad de que los personajes que les venían a la cabeza pertenecieran a la época medieval. Es decir, conocían personajes como Ricardo Corazón de León o el Cid Campeador, pero no tenían la seguridad de fuesen medievales, ni siquiera de que fuesen personajes reales.

Igualmente sorprendente resulta que el $53 \%$ de los encuestados diese como respuesta entre 1 y 4 nombres, frente a un $21 \%$ que mencionan entre 5 y 10 nombres, y un solo alumno capaz de dar más de 10 nombres identificados con la Edad Media. Un $29 \%$ de los alumnos, además, incluyó algún tipo de error conceptual en sus respuestas. Lo más habitual fue el anacronismo, que en ocasiones alcanzó un nivel aberrante cuando en algún caso se llegó a citar a Cervantes, o incluso a Napoleón como personaje medieval. También hubo casos residuales de nombres míticos mencionados como reales, en concreto los relacionados con los mitos artúricos: Arturo, Camelot...

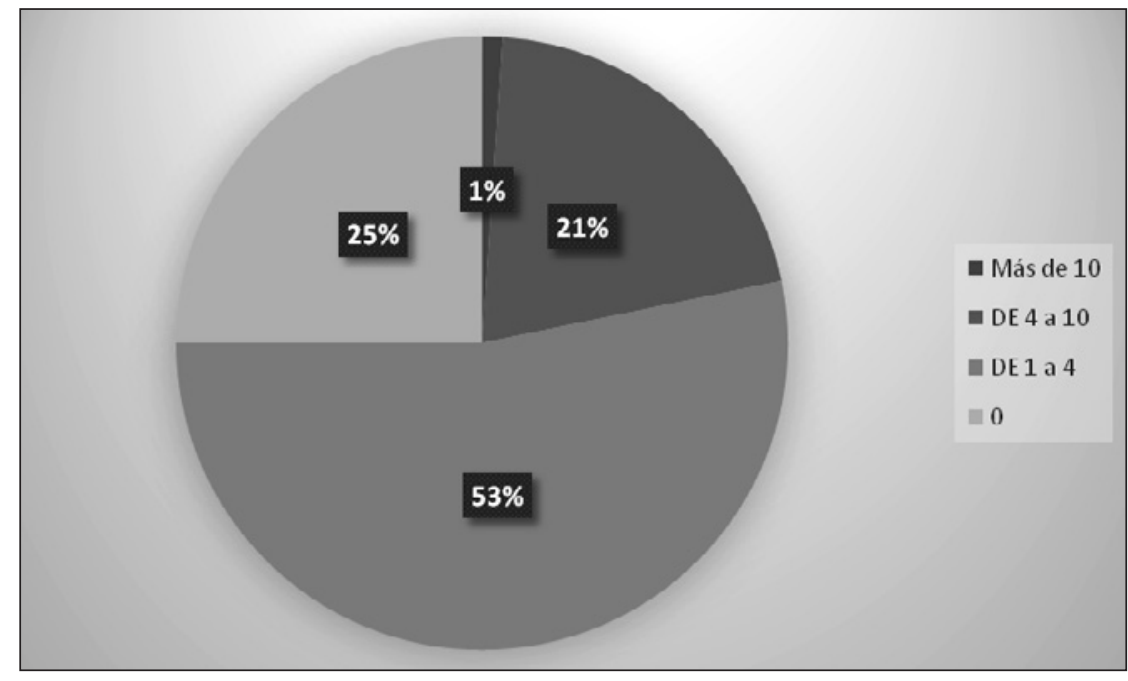

Gráfico 3. $N^{\circ}$ de respuestas a la pregunta:

"Menciona los nombres propios de época medieval que conozcas"

En cuanto a los nombres más representados en las respuestas de los alumnos, se debe destacar la presencia de muchos geográfico-políticos que enlazan con la actualidad, como los de las coronas de Castilla o Aragón; también el predominio de personajes propios de la Historia política y militar; y finalmente, la ausencia casi total de nombres referidos a la alta Edad Media, o incluso, la presencia preferente de nombres relativos al final de la Edad Media, como los Reyes Católicos o Colón (personajes pertenecientes al ocaso del periodo). 


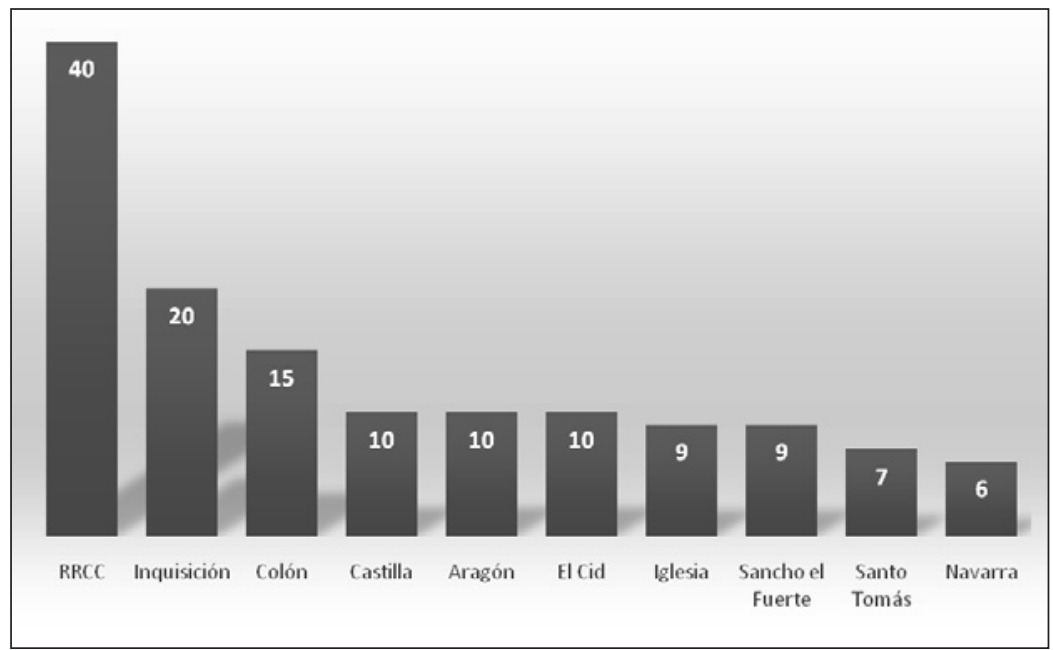

Gráfico 4. Respuestas más frecuentes de los alumnos a la pregunta: "Menciona nombres propios de época medieval que conozcas"

Finalmente, cabe añadir que la relación de nombres propios de persona fue muy escasa. Los alumnos recordaron mejor los nombres de instituciones, y cuando recordaron los nombres de algunos personajes fueron los relacionados con la historia militar del enfrentamiento entre cristianos y musulmanes (El Cid y Sancho VII el fuerte, rey de Navarra), o con los hechos de finales de la Edad Media en la península (quizás debido a la reciente emisión de la serie Isabel, sobre los Reyes Católicos, en la televisión).

\section{Personajes considerados medievales por el alumnado}

Otra de las formas utilizadas para conocer qué entienden por Edad Media los alumnos, fue preguntar por una serie de personajes históricos, de épocas diferentes, y relacionados con un tipo de Historia también variada: política, social, cultural... En la lista había literatos, pintores, intelectuales, políticos, guerreros, clérigos... todos ellos personajes de gran relevancia. Éramos conscientes de que los alumnos no conocían a todos los personajes, y que en algunos casos la cronología próxima al final de la Edad Media podía llevar a confusión (por ejemplo con Maquiavelo, Fernando el Católico, Leonardo Da Vinci o Erasmo de Rotterdam). Sin embargo, no se trataba de un ejercicio de precisión cronológica o de un examen de conocimientos para evaluar o criticar la calidad de nuestra Educación Secundaria. Se pretendía conocer algo más sobre los criterios utilizados por el alumnado para intuir si un personaje pertenecía o no a la Edad Media.

Los mayores porcentajes de acierto se producen en personajes de la historia política, ya sean medievales o no. El personaje más acertado fue el rey aragonés Fernando el Católico, que fue considerado como un personaje medieval, aunque es cierto que la cronología de su reinado podría llevar a alguna confusión. 
Por encima del $80 \%$ de acierto se sitúan las respuestas sobre personajes como Julio César, Octavio Augusto, Alfonso X el Sabio o el Cid. Entre los primeros puestos, sólo Séneca se incluye entre aquellos nombres que tienen una connotación de tipo cultural. Logran también buenos resultados -si bien no tan brillantes- los santos de época medieval, en concreto Santo Tomás de Aquino, y San Francisco de Asís. Sólo el $38 \%$ acertó en cambio que San Ignacio de Loyola no es un santo de época medieval. La lógica aplicada por los alumnos parece sencilla: los santos fueron incluidos por muchos alumnos de manera sistemática dentro de la Edad Media. En el caso de San Ignacio, creemos que el error revela el criterio utilizado por el grueso de los alumnos en sus respuestas.

Otra cuestión interesante es el bajo nivel de aciertos registrado en el caso de los nombres correspondientes a la alta Edad Media. Así, el paradigmático Carlomagno sólo es relacionado con la Edad Media por un 45\% de los alumnos, Leovigildo por un 41 \% (aunque su atribución al periodo medieval podría ser discutible), Abderramán (genérico, sin numeral), por un 52\%, y especialmente Mahoma, por tan solo un $15 \%$ de los alumnos. Parece como si en la actualidad la representación social más extendida sobre el medievo se identificase, precisamente, con imágenes ligadas al final del periodo.

En cuanto a los nombres de artistas y literatos, es Ilamativo el bajo nivel de acierto en personajes como Giotto (20\%), Dante (25\%) o Maquiavelo (29\%). Los alumnos reconocían los nombres, pero eran incapaces de situarlos en una época concreta.

Por tanto, la sensación es que los alumnos relacionan cronológicamente con más corrección a los personajes de la historia política. Su capacidad de reconocer simul-

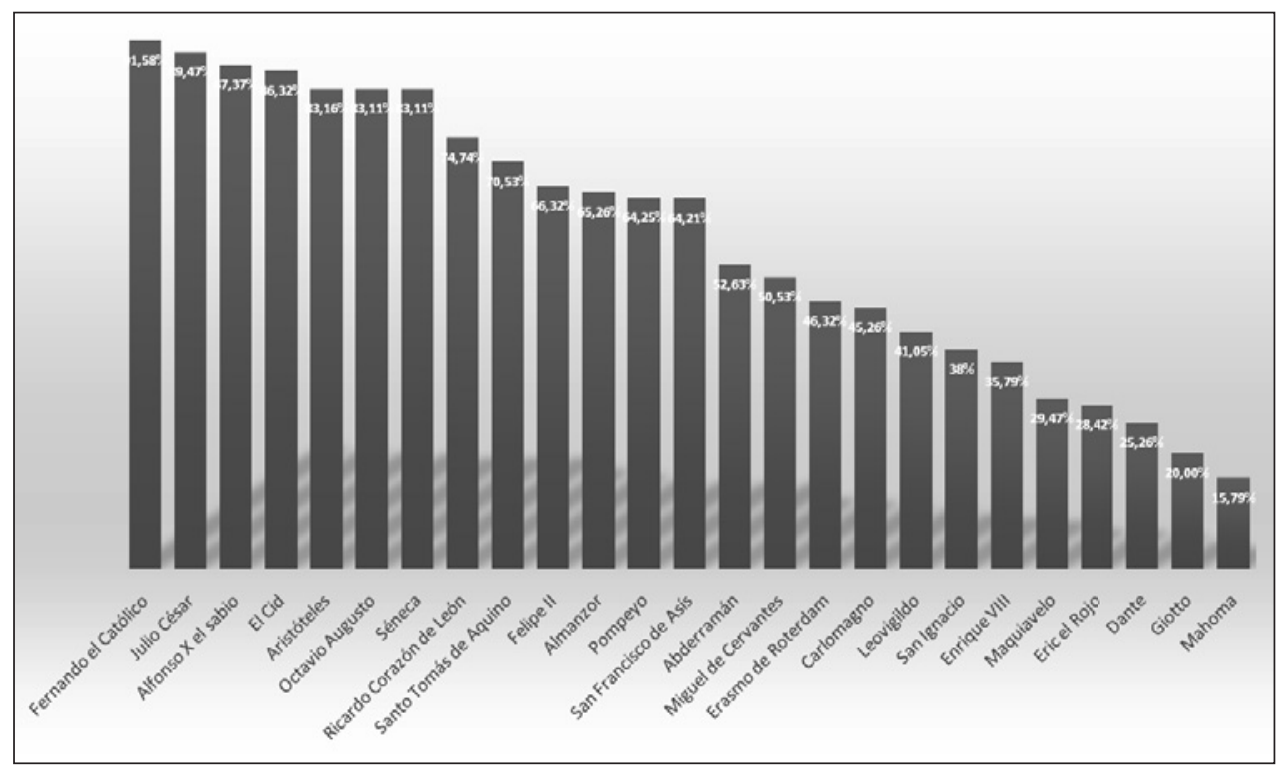

Gráfico 5. Porcentaje de acierto en la ubicación cronológica (Edad Media o no) de diferentes personajes históricos 
taneidades o pertenencias a periodos históricos para personajes de otro tipo (artistas o literatos), es muy reducida, lo que hace pensar en la necesidad de utilizar líneas de tiempo complejas y relacionales en educación. Parece como si los personajes de tipo político fueran asociados a imágenes o atributos que sí son entendidos como propios de la Edad Media (la espada, la corona, la armadura), frente a los artistas, que no poseen esos atributos, sino otros que no son entendidos como propios de la Edad Media (la pluma, el pincel, el escritorio...), lo que enlaza directamente con la conocida tesis de Jacques Heers sobre "la invención de la Edad Media" y el papel que juega el concepto de "renacimiento".

Por último, una cuestión también interesante es la visión europeísta y cristiana que poseen los alumnos de la Edad Media. Prácticamente olvidan referirse al mundo musulmán, y cuando se les pide reconocer al profeta Mahoma como un personaje propio del Medievo, lo omiten de manera muy mayoritaria.

\section{Procedimiento didáctico}

\section{Alumnos del grado de Maestro}

Finalmente, se pretende realizar una evaluación cualitativa de los trabajos realizados en grupo, en busca de diferentes tipos de representaciones sociales de la Historia. El trabajo de indagación tenía básicamente dos partes: la búsqueda de representaciones sociales de la Historia en fuentes de información no científicas (prensa, novela, cine, cómic, videojuegos, redes sociales, Youtube, internet en general...), que se plasmó en una presentación con diapositivas (Power Point) que mezclaba texto e imagen; y la búsqueda de fuentes de información científicas (monografías o artículos de revista localizados en buscadores académicos como Dialnet o Google Scholar) para conocer algo más sobre la realidad histórica estudiada.

Como primera observación podemos afirmar que los alumnos del grado se interesaron mucho más en la búsqueda de tópicos concretos (por ejemplo, el uso metafórico de conceptos históricos en la prensa deportiva, como hispanos, gladiadores, coliseo, vikingos...), que en representaciones sociales más elaboradas (por ejemplo, la identificación del Imperio Romano con la civilización, y del mundo germánico con la destrucción y el atraso). La elección de representaciones muy simples o meramente anecdóticas tendió a ser reflejo de una comprensión parcial del sentido de la actividad. De igual modo, mientras la elaboración del Power Point por medio de imágenes era realizada de manera correcta por la casi totalidad de los grupos, los problemas aparecían, progresivamente, conforme se pedía un mayor nivel de explicación. Los alumnos eran capaces de localizar informaciones, pero no siempre de procesarlas para responder de forma general a la actividad propuesta. En este sentido, las actividades que han resultado más complejas para los alumnos se han ordenado (de menor a mayor dificultad) del siguiente modo:

1. Localización por medio de imágenes obtenidas con el buscador Google de representaciones sociales de la Historia, erróneas o no.

2. Explicación del significado de las imágenes, es decir, de las propias representaciones sociales. 
3. Elección de fuentes secundarias para contrastar las informaciones localizadas en Google.

4. Lectura y comprensión (explicación) de las informaciones obtenidas a través de las fuentes secundarias.

5. Elaboración de un discurso coherente entre ambas realidades (la Historia popular y la Historia científica, según las denominaciones utilizadas por M. Carretero).

6. Búsqueda del origen del error.

7. Propuesta de una forma de comprensión alternativa.

En cualquier caso, insistimos en el interés despertado entre los alumnos por esta actividad, y en especial por la primera parte, a tenor de los comportamientos en clase, de la implicación en la tarea de casi todos los grupos, de la extensión de los trabajos, y del alto porcentaje de acierto en la elección de los materiales. Fueron pocos los alumnos que se limitaron a responder a la actividad de un modo rutinario. Por tanto, se pudo comprobar que el trabajo a partir de las representaciones sociales de la Historia sirvió como aliciente para el desarrollo de la investigación posterior y para lograr la implicación de los alumnos.

En cambio fueron menos exitosos los resultados de la parte científica del procedimiento. Esta vertiente del ejercicio implicaba buscar bibliografía científica, leerla y seleccionar las informaciones relacionadas con las representaciones sociales seleccionadas. Es decir, esta segunda parte se convertía en el objetivo principal del trabajo, y no siempre los resultados fueron los esperados: en bastantes casos las respuestas fueron escasas en cuanto a su extensión, y superficiales en su planteamiento. En comparación, los alumnos prefirieron globalmente la actividad de investigación y búsqueda de información, a la actividad de análisis y lectura de la bibliografía. La búsqueda de informaciones en los buscadores científicos -ya trabajados previamente en otra práctica- resultó una actividad a la que los alumnos se enfrentaron con cierta solvencia, aunque no en todos los casos. Para dirigir las búsquedas se les facilitó los términos más adecuados, entre los cuales se incluían las palabras "tópico" y "estereotipo", junto a los conceptos relacionados con la época a estudiar.

Sin embargo, una vez que se había llegado a encontrar los materiales más adecuados para lograr el éxito en la tarea, fueron varios los grupos que no supieron aprovechar las lecturas realizadas. Dos factores principales influyeron en esta circunstancia: la falta de hábito en el manejo de literatura científica (aun cuando se terminó por escoger sólo los materiales más óptimos para el trabajo y de limitada extensión), y en segundo lugar, la falta de literatura de alta divulgación que sirva para la formación en un nivel inmediatamente inferior al científico. Estas características de los alumnos no resultan extrañas, y casan bien con el perfil que algunos autores muestran sobre los alumnos en la actualidad (García García y Alonso Magdaleno, 2013): hábiles en la búsqueda de informaciones, pero con dificultades a la hora de analizar los resultados obtenidos. Su origen se puede situar en el desconocimiento de la Historia por parte de los alumnos, y en la falta de costumbre en el trabajo con literatura científica. En el futuro, esta actividad intentará asociarse a lecturas expertas previas, totalmente dirigidas por el docente, que permitan a los alumnos conocer el periodo que estudian antes de acometer el análisis de las representaciones sociales más extendidas en la actualidad sobre él. 
Con todo, las respuestas de los alumnos de grado indican que en líneas generales comprendieron con bastante precisión el concepto de representaciones sociales de la Historia, y que se consiguió instalar en ellos la duda sobre la fiabilidad de las fuentes de información no científicas, y la necesidad de contrastar las informaciones. En cada uno de los temas históricos los alumnos detectaron la presencia de anacronismos, realidades míticas o alternativas, simplificaciones, lugares comunes e hipérboles o exageraciones. Desde quienes analizaron los errores en las interpretaciones del Far West, hasta quienes se ocuparon de la prehistoria, los planteamientos fueron correctos en casi todos los casos.

\section{Alumnos del Curso de Adaptación a los grados de Maestro}

La diferencia principal de los trabajos de estos alumnos con respecto a los realizados por los alumnos del grado fue la de encontrar mayores dificultades en las búsquedas de información -especialmente importantes en los individuos de mayor edad- y en cambio lograr una mayor profundidad en el análisis de la bibliografía experta. La actividad resultó en todos los casos igual de motivadora que en el Grado, pero en algunos casos estos trabajos revistieron una gran calidad en sus planteamientos históricos, aun cuando los alumnos no eran expertos en Historia. Sin duda alguna, el trabajo con las representaciones sociales de la Historia constituyó un estímulo para la investigación del tema y -a diferencia de los alumnos del Grado-, en este caso fueron bastantes los alumnos que supieron aprovechar los materiales expertos utilizados en sus trabajos, consiguieron resolver el conflicto, encontrar en algunos casos el origen de los tópicos y estereotipos, y formular una explicación correcta que discurría en paralelo junto a representaciones sociales complejas.

En un caso concreto, una alumna -maestra en ejercicio- fue capaz de rastrear y leer bibliografía en inglés sobre el "Salvaje Oeste" para dar una explicación multicausal del origen del medio Oeste americano, de sus formas de vida y de su economía, basadas en la explotación ganadera por medio de campos abiertos. En este caso, la figura del cowboy quedaba perfectamente encuadrada y explicada en su contexto histórico por medio de un análisis de tipo social, económico y cultural, que resaltaba especialmente en su comparación con los tópicos extendidos en las pantallas de cine por el western.

\section{Master de Formación del Profesorado de Educación Secundaria}

En conjunto, los alumnos del Máster de Formación del Profesorado de Educación Secundaria fueron quienes afrontaron la tarea con mayor eficiencia, tanto en las búsquedas del saber popular y del saber experto, como en el análisis de los recursos haIlados. Evidentemente el resultado era esperado, por cuanto en la mayoría de los casos los alumnos eran licenciados o graduados en Historia, Geografía, Humanidades, Historia del Arte o Ciencias Políticas. Las representaciones sociales elegidas por estos alumnos no resultaron en ningún caso superficiales, ni limitadas a detalles, e incluso conseguían presentar la problemática desde perspectivas diferentes y complementarias, en términos de evolución de la comprensión del propio concepto histórico y de degradación progresiva de su relación con la realidad histórica. Por ejemplo, al 
analizar el tema de los vikingos, varios alumnos fueron capaces de señalar que existe un estereotipo muy ligado a la percepción visual de los vikingos, que se manifiesta de muy diferentes maneras en la actualidad (disfraces, emblemas, publicidad, cine y televisión...), y que se asocia de modo simplista a dos o tres ideas básicas (raza, violencia, fuerza, excesos e ignorancia). En las representaciones elegidas, los alumnos aprecian un gran esquematismo y una progresiva simplificación de los atributos pertenecientes a los vikingos. Sus explicaciones eran complejas y mostraban haber llegado a comprender las diferentes facetas de la tarea. Quizás la parcela más compleja y no siempre resuelta, fue la de hallar el origen de algunas de estas representaciones sociales, cuestión que evidentemente no es sencilla y requeriría en la mayor parte de los casos un análisis más sosegado.

\section{Conclusiones}

En el transcurso de la investigación se ha podido detectar en las aulas universitarias la presencia de diversas construcciones sociales estereotipadas sobre la Edad Media. En los alumnos del Grado de Maestro parece bastante arraigada la idea de una Edad Media que encarna valores antagónicos a los de nuestra sociedad: intolerancia, violencia, injusticia, abuso de poder... Estos son los aspectos que los alumnos destacan en la Edad Media, y por lo tanto los que caracterizarían a aquel periodo, a diferencia de nuestro presente. Esa Edad Media, además, parece muy centrada en conceptos relacionados con la Historia militar de la época. En este punto, creemos que las nuevas propuestas educativas sobre la Edad Media deberían tratar de minimizar el efecto de estos tópicos por medio de propuestas de otros más precisos, que compartimenten y detallen más la Edad Media, y por medio del uso de líneas de tiempo que alejen la comprensión de un periodo de mil años en torno a una imagen monolítica que gira en torno al caballero, al castillo $y$, en un segundo plano, a la Iglesia.

Sobre procedimiento didáctico diseñado en este trabajo, estimamos que ha resultado de interés para dar a conocer la naturaleza de la Historia como Ciencia Social en permanente construcción, la importancia del método científico y del rigor en el uso y el contraste de las fuentes de información, y la relevancia de la Historia como elemento cultural en nuestro presente. Los alumnos han entendido la tarea como un trabajo útil y cercano a su experiencia, lo que en muchos casos ha estimulado el acercamiento a las fuentes de información expertas.

La faceta más cuestionable del procedimiento se refiere por el momento a su utilidad para lograr aprendizajes curriculares conceptuales relacionados con la Historia. Las investigaciones y análisis de los alumnos de Grado se han quedado muchas veces en reflexiones superficiales, y el aprendizaje de contenido propiamente histórico ha sido escaso. En esta línea, la finalidad del proyecto era su puesta en práctica en aulas de Educación Secundaria, aunque este fracaso puntual de los alumnos del Grado de Maestro en algunas facetas del procedimiento, obliga a reflexionar de nuevo sobre ello.

En nuestra opinión, la búsqueda de recursos bibliográficos adecuados para esta tarea concreta, tan limitada en el tiempo, debe corresponder al profesor. Los alumnos perdieron un tiempo precioso en realizar búsquedas -aunque ya manejaban con 
cierta soltura los buscadores científicos-, y han dedicado menos tiempo a la lectura de los materiales. Ante la falta de tiempo para el planteamiento de una actividad completa de indagación y análisis, creemos que la indagación podría limitarse a la búsqueda de representaciones sociales por la red -tarea que resulta grata a los alumnos y que propicia su motivación- y a un posterior análisis de materiales previamente seleccionados por el profesor. De esta manera, el procedimiento también podría ser llevado a la práctica en aulas de Secundaria, donde seguiremos ensayando con las representaciones sociales de la Historia en un futuro próximo.

\section{REFERENCIAS BIBLIOGRÁFICAS}

Astolfi, J. P. (1997). L'erreur, un outil pour enseigner. París: ESF.

Barrio, J. A. (2008). La Edad Media en el cine de Estados Unidos. Imago Temporis. Medium Aevum, 2, 426-452.

Briceño, E., y Milagros, T. (2009). El uso del error en los ambientes de aprendizaje: Una visión transdisciplinaria. Revista de Teoría y Didáctica de las Ciencias Sociales, 14, 9-28.

Cano Alonso, P. L. (2014). Cine de romanos. Apuntes sobre la tradición cinematográfica y televisiva del Mundo Clásico. Madrid: Centro de Lingüística Aplicada Atenea.

Carretero, M., Rosa, A., y González, M. F. (2006). Introducción. Enseñar Historia en tiempos de Memoria. En M. Carretero, A. Rosa y M. F. González (Eds.), Enseñanza de la Historia y memoria colectiva (pp. 13-38). Buenos Aires: Paidós.

Carretero, M. (2007). Documentos de identidad. La construcción de la memoria histórica en un mundo global. Buenos Aires: Paidós.

Carretero, M., Pozo, J. I., y Asensio, M. (1989). Problemas y perspectivas en la enseñanza de las Ciencias Sociales: Una concepción cognitiva. En M. Carretero, J. I. Pozo y M. Asensio (Comps.), La enseñanza de las Ciencias Sociales (pp. 13-29). Madrid: Visor.

Castillejo Cambra, E. (2008). Mito, legitimación y violencia simbólica en los manuales escolares de Historia del franquismo. Madrid: UNED.

Espinosa Maestre, F. (2006). Contra el olvido. Historia y memoria de la guerra civil. Barcelona: Crítica.

Falcón, L., y Díaz Aguado, Ma . J. (2014). Relatos audiovisuales de ficción sobre la identidad adolescente en contextos escolares. Comunicar, 42, 147-155.

Ferrés, J. (2000). Educar en una cultura del espectáculo. Barcelona: Paidós.

Fornis, C. (2011). Un sendero de tópicos y falacias: Esparta en la ficción y en la Historia popular. SPAL, 20, 43-51.

Galván Freile, F. (2008). La imagen de la Edad Media en el cómic: entre la fantasía, el mito y la realidad. Revista de poética medieval, 21, 125-173.

García Gual, C. (2002). El poder de la ficción: novela histórica y Edad Media. Barcelona: Península.

García García, J., y Alonso Magdaleno, M. I. (2013). Estudio sobre el comportamiento del alumnado en la realización de trabajos escritos. RELATEC: Revista Latinoamericana de Tecnología Educativa, 12(2), 143-152. 
García Pujades, S. (2013). La Edad Media de los alumnos de educación secundaria: Conceptos e Ideas previas. Clío, History and History Teaching, 39.

González, F. M., Morón, C., y Novak, J. D. (2001).Errores conceptuales. Diagnosis, tratamiento y reflexiones, Pamplona: Eunate.

González, F. M., y Novak, J. D. (1993). Aprendizaje significativo: técnicas y aplicaciones. Madrid: Cincel.

Grupo Valladolid (1994). La comprensión de la Historia por los adolescentes. Valladolid: Universidad de Valladolid.

Halbwachs, M. (2004). La memoria colectiva. Zaragoza: Prensas Universitarias de Zaragoza.

Jiménez Alcázar, J. F. (2011). El otro pasado posible: la simulación del medievo en los videojuegos. Imago Temporis. Medium Aevum, 5, 491-517.

Jodelet, D. (1989). Représentations sociales: un domaine en expansión. En D. Jodelet (Dir.), Les représentations sociales (pp. 31-61). París: Presses Universitaires de France.

Liceras Ruiz, A. (2003). Tópicos, estereotipos y prejuicios, componentes de un aprendizaje informal que deforma. Iber: Didáctica de las ciencias sociales, geografía e historia, 36, 89-101.

Martos Núñez, E., y Martos García, A. (2012). Imaginarios del Devoramiento en la cultura del agua: Dragones, Targantía, Tragaldabas y otros espantos. Implicaciones didácticas. Indivisa. Boletín de Estudios de Investigación, 13, 122-143.

Moliner, P. (2001). Formation et stabilisation des représentations sociales. En P. Moliner (Dir.), La dynamique des représentations sociales (pp. 15-41). Grenoble: Presses Universitaires de Grenoble.

Moscovici, S. (1989). Des representations collectives aux représentations sociales: éléments pour une histoire. En D. Jodelet (Dir.), Les représentations sociales (pp. 62-86). París: Presses Universitaires de France.

Mugueta Moreno, Í., y Tobalina Oraá, E. (2014). Medievo digital o medievo popular: representaciones sociales de la Edad Media en las comunidades de Gamerson Line. Miscelánea Medieval Murciana, 38, 161-179.

Navarro Espinach, G. (2011). Cultura visual y enseñanza de la Historia. La percepción de la Edad Media. Educación Artística Revista de Investigación, 2, 153-160.

Ortega Alcántara, L. (2007). La película 300: defensa de la bella muerte en la guerra. Isla de Arriarán, 30, 259-262.

Prieto Arciniega, A. (2005). Troya sin Homero: Troya (2004). Studia Histórica. Historia Antigua, 23, 23-37.

Prieto Arciniega, A. (2011). La Antigüedad a través del cine. Barcelona: Publications Universitat de Barcelona.

Rivero Gracia, P. (2009). El aprendizaje del mundo romano: fuentes de conocimiento no formal del alumnado de secundaria. Didáctica de las ciencias experimentales y sociales. 23, 23-37.

Rodríguez Salazar, T., y García Curiel, M. L. (Coords.) (2007). Representaciones sociales. Teoría e investigación. Guadalajara: Universidad de Guadalajara. 
Ruiz Torres, P. (2007). Los discursos de la memoria histórica en España. Hispania Nova. Revista de Historia Contemporánea. 7. Recuperado de http://hispanianova. rediris.es/7/dossier/07d001.pdf.

Ruiz-Domècec, J. E. (2009). El poder de la ficción: novela histórica y Edad Media. En La Historia Medieval Hoy: percepción académica y percepción social. XXXV Semana de Estudios Medievales de Estella (pp. 247-261). Pamplona: Gobierno de Navarra.

Sánchez Rivera, J. Á. (2013). Seguir la corriente o navegar sobre las olas: una reflexión acerca del patrimonio histórico-artístico, los mass media y su valor didáctico. Clío, 39.

Sanz, J. L. (2009). Los dinosaurios, un mito cultural. Revista Digital Universitaria, $10(2)$.

Serrano Lozano, D. (2012). Cine y Antigüedad: pasado y presente en la pequeña y gran pantalla. Historia Autónoma, 1, 37-52.

Sosa, F., Bombelli, J. I., Fernández, O, Cejas, L., Barreiro, A., y Zubieta, E. (2013). Representaciones sociales de la Historia: creencias, sentimientos e importancia de figuras de la Historia argentina. Anuario de Investigaciones. Facultad de Psicología de Buenos Aires, 20(1), 241-250.

Tribó Travería, G. (2005). Enseñar a pensar históricamente. Los archivos y las fuentes documentales en la enseñanza de la Historia. Barcelona: Ice/Horsori.

Wandersee, J. H., Mintzes, J. J., y Novak, J.D. (1994). Learning: Alternative Conceptions. En D. Gabel (Ed.), Handbook on research in Science Teaching (pp. 177210). Washington: National Science Teachers Asociation DC.

Zaragoza, G. (1989). La investigación y la formación del pensamiento histórico del adolescente. En M. Carretero, J. I. Pozo y M. Asensio (Comps.), La enseñanza de las Ciencias Sociales (pp. 165-177). Madrid: Visor. 